\title{
Relationship of carotid intima-media thickness and duration of vegetarian diet in Chinese male vegetarians
}

\author{
Shu-Yu Yang ${ }^{1,2^{*}}$, Hui-Jie Zhang ${ }^{2+}$, Su-Yun Sun ${ }^{2}$, Li-Ying Wang ${ }^{2}$, Bing Yan², Chang-Qin Liư ${ }^{2}$, Wei Zhang ${ }^{2}$ and
} Xue-Jun Li ${ }^{2}$

\begin{abstract}
Objective: Many studies have shown that vegetarian diet has beneficial effects on the prevention of cardiovascular diseases. However, the effect of vegetarian diet on carotid intima-media thickness (IMT), as well as the association between IMT and duration of vegetarian diet, are still unclear. The present study aims to investigate the influence of duration of vegetarian diet on cardiovascular risk factors, and more importantly on IMT among Chinese vegetarians.
\end{abstract}

Methods: One hundred and seventy-one Chinese male vegetarians were screened for metabolic profile, cardiovascular risk and carotid IMT. They were compared with 129 age-matched omnivores recruited from a community-based health project. The effects of confounding factors were adjusted by stepwise logistic regression analysis.

Results: Compared to the omnivores, the vegetarians had lower BMI, weight, systolic blood pressure and diastolic blood pressure. Also, the levels of triglyceride, total cholesterol, HDL-Cholesterol, LDL-Cholesterol, ApoA1, ApoB, uric acid, albumin and $\gamma$-glutamyltransferase were significantly reduced in vegetarians. Omnivores had significantly higher fasting blood glucose than that of vegetarians. However, there were no differences in fasting insulin, Creactive protein and HOMA-IR between the two groups. IMT was thinner in the vegetarian group than in the omnivore group ( $0.59 \pm 0.16$ vs. $0.63 \pm 0.10 \mathrm{~cm}, P<0.05)$. The vegetarians were divided according to duration of vegetarian diet ( $<6$ years, 6 to $\leq 11$ years, $>11$ years), those in tertile 1 ( $<6$ years) and tertile 2 ( 6 to $\leq 11$ years) had shown thinner IMT as compared to the omnivores, and tertile 3 had shown no reduction.

Conclusion: A decrease in multiple cardiovascular risk factors such as BMI, blood pressure and lipid profile was associated with vegetarian diet. Moreover, taking a low-calorie, low-protein, or vegetarian diet might have great beneficial effects on IMT through improved lipid profile, and the beneficial effects appeared to be correlated with the duration of vegetarian diet.

Keywords: vegetarian diet, IMT, duration of vegetarian diet

\section{Introduction}

The effects of vegetarian diets on the prevention of cardiovascular diseases (CVD) had been reported extensively. As a specific population which has successfully made long-term lifestyle modifications, the vegetarian diet could provide important insights into the potential

\footnotetext{
* Correspondence: yang.shuyu@yahoo.com.cn

† Contributed equally

${ }^{1}$ Fujian Academy of Integrative Medicine, Fujian University of Traditional Chinese Medicine, 1 Hua-Tuo Road, Shang-Jie Town, Fuzhou, 350108, PR China

Full list of author information is available at the end of the article
}

efficacy of a diet in reducing cardiometabolic risk. Many studies have shown that vegetarians had both lower blood pressure and cardiovascular mortality as compared with omnivores [1-3], and the benefit was attributed to a more favorable lipid profile due to long-term low calorie low-protein vegetarian diet [4]. However, some others did not show the beneficial effects of vegetarian diet $[5,6]$.

Carotid IMT has been shown to predict CVD and is able to provide a surrogate end point to assess early atherosclerosis $[7,8]$; however, whether vegetarian diet
C Biomed Central

() 2011 Yang et al; licensee BioMed Central Ltd. This is an Open Access article distributed under the terms of the Creative Commons Attribution License (http://creativecommons.org/licenses/by/2.0), which permits unrestricted use, distribution, and reproduction in any medium, provided the original work is properly cited. 
could improve IMT is unclear. Furthermore, the association of the duration of vegetarian diet and IMT is still not established. The purpose of the present study was to investigate the protective effects of vegetarian diet on cardiometabolic risk, such as IMT, lipid profile, blood pressure and insulin sensitivity, and the relationship between its beneficial effects and duration of vegetarian diet in Chinese male vegetarians.

\section{Subjects and methods Subjects}

One hundred and seventy-one vegetarians (age range: 21-76 years, mean age: $32.6 \pm 12.7$ ) were recruited from Nanputuo Temple of Xiamen in China. They did not take meat or fish as according to their religious beliefs, but a small part would occasionally consumed eggs and milk. The participants were on vegetarian diet at least one year (mean 10.4 \pm 8.0 years, range, $1-44$ years). The control group included 129 matched healthy omnivorous men from a community-based health project in Xiamen; no vitamins were taken during the previous 6 months, and were not on a lipid-lowering or weight-loss diets. The major study exclusion criteria were as follows: body weight $\geqq 120 \%$ of ideal, a history of chronic disease (renal disease, cancer, diabetes mellitus, heart disease, and hypertension), alcohol intake, and current cigarette smoking. All subjects signed informed consents, and the study protocol was approved by the Human Research Ethics Committee of the First Hospital Affiliated to Xiamen University.

\section{Study protocol \\ Dietary assessment}

Subjects were interviewed and the average of three $24 \mathrm{~h}$ dietary recalls (two on week days and one on weekends) were used to estimate daily consumption of different nutrients. A database for Chinese food composition was used to calculate the daily energy and nutrient intake $[9,10]$.

\section{Clinical assessment and laboratory measurements}

All subjects were screened for health status by means of questionnaires regarding past medical history, family history, dietary preferences, starting age and duration of vegetarian diet and personal data, such as smoking status, alcohol consumption, education level, and physical exercise status. After a 10 to $12 \mathrm{~h}$ overnight fasting, subjects received anthropometric and biochemical measurements. Anthropometric measurements include weight, height, waist circumference, blood pressure (BP) and body mass index (BMI).

Serum lipids, including triglyceride (TG), total cholesterol (TC), high-density lipoprotein cholesterol (HDLC), apolipoprotein A1 (ApoA1) and apolipoprotein B $(\mathrm{ApoB})$; including total protein (TP), albumin (ALB), $\gamma$ - glutamyl transferase $(\gamma-\mathrm{GT})$; homocysteine (HCY), uric acid (UA) were assayed by enzymatic methods with automatic multi-channel chemical analyzer (Hitachi 7450, Hitachi Corp., Tokyo, Japan). Low-density lipoprotein cholesterol (LDL-C) was calculated by Friedewald's formula. Fasting glucose was determined by the glucose oxidase method using a Monarch Chemistry 2000 Autoanalyzer (Instrumentation Laboratory, Oakbrook Terrace, IL, USA) through standard laboratory techniques. Serum fasting insulin concentrations were measured by electrochemiluminiscence immunoassay (Roche Elecsys Insulin Test, Roche Diagnostics, Mannheim, Germany). HOMA-insulin resistance (HOMA-IR) was calculated by fasting serum insulin (FIns, $\mathrm{mU} / \mathrm{ml}$ ) $\times$ fasting blood glucose (FBG, mmol/l)/22.5. C-reactive protein (CRP) was assayed in one batch by use of an immunoassay method (BN ProSpec System, Dade Behring, Marburg, Germany).

\section{Measurement of carotid artery IMT}

All subjects underwent B-mode ultrasonography of the extracranial carotid arteries by the use of a duplex system (a high-resolution ultrasound instrument ATL, HDI 5000, Phillips Sistemi Medical, Bothell, WA, USA) with a 7 - to $10-\mathrm{MHz}$ linear array multi-frequency transducer). All the examinations were performed by the same ultrasonographer blinded to clinical information. The right and left common carotid arteries and internal carotid arteries (including bifurcations) were evaluated with the subjects in supine position, with the head turned away from the sonographer and the neck extended with mild rotation. The intima-media thickness (IMT), defined as the distance between the intimal-luminal interface and the medial-adventitial interface, was measured. Briefly, in posterior approach and with the sound beam set perpendicular to the arterial surface, $1 \mathrm{~cm}$ from the bifurcation, three longitudinal measurements of IMT were completed and the mean value of six measurements from right (IMT-R) and left (IMT-L) carotid arteries were used. The mean IMT was the average of the IMTs from the right and left carotid arteries. Plaque, detected in longitudinal and transverse planes with anterior, lateral, and posterior approaches, was defined as an echogenic focal structure encroaching the vessel lumen with a distinct area $50 \%$ greater than the IMT of neighboring sites. The average absolute difference and standard deviation between measurements for 30 participants who had replicate maximum IMT measurements was $0.02 \pm 0.04 \mathrm{~mm}$.

\section{Statistical analysis}

Statistical analyses were performed with SAS, version 8.01. Data are presented as means \pm standard deviation (S.D) or means (95\% confidence interval). Data that were not normally distributed were logarithmically 
transformed before analysis. Unpaired Student's t-test (or Manne Whitney U-test) and chi-square test were used for testing differences for numerical and nominal variables. The $\chi^{2}$-test was used to compare categorical variables between groups. The correlation of duration of vegetarian diet with metabolic parameters was analyzed by Pearson correlation and multivariate linear regression analysis. The vegetarians were classified into three tertiles according to the duration of vegetarian diet or age of starting vegetarian diet respectively. The differenced groups were compared using an ANOVA test. The definition of the upper normal limit of IMT was set at the 75 th upper percentile of the IMT distribution in controls [11]. Multiple logistic regression analysis was used to assess the odds ratio (OR) for the presence of thick IMT according to tertiles of duration of vegetarian diet and age of starting vegetarian diet. Two-sided values of $P<0.05$ were considered significant.

\section{Results}

\section{Clinical characteristics of subjects}

The vegetarians consumed less energy, protein, and fat than the omnivores (Additional File 1 Table S1); this is consistent with the lower plasma concentrations of total protein, triglycerides and cholesterol in vegetarians.
Total fiber and polyunsaturated fatty acids (PUFA) intakes were similar between the two groups, whereas relative saturated fatty acid (SFA) and monounsaturated fatty acids (MUFA) intake were significantly lower in the vegetarians.

Characteristics of all subjects are shown in Table 1 and there were no significant differences in age and waist circumference between the two groups. Compared to the omnivores, the vegetarians had lower BMI, weight, systolic BP and diastolic BP. Also, the levels of TG, TC, HDL-C, LDL-C, ApoA1, ApoB, UA, ALB and $\gamma$-GT were significantly reduced in vegetarians. Omnivores had significantly higher FBG than the vegetarians. However, there were no differences in fasting serum insulin, C-reactive protein and HOMA-IR between the two groups.

As far as IMT was concerned, there was significantly difference between the two groups $(P<0.05)$. The mean value for the IMT in the right carotid arteries $(0.59 \pm 0.15$ vs. $0.62 \pm 0.09 \mathrm{~cm})$ and left carotid arteries, $(0.59 \pm 0.15$ vs. $0.62 \pm 0.09 \mathrm{~cm})(P<0.05)$ were calculated. After controlling the age, smoking, drinking, and history of disease, the vegetarians still had thinner IMT as compared to that of the omnivores (data not shown).

Table 1 Baseline characteristics of the subjects

\begin{tabular}{|c|c|c|c|}
\hline Variables & Vegetarians $(n=171)$ & Omnivores $(n=129)$ & $P$ \\
\hline Age (yrs) & $32.6 \pm 12.7$ & $34.2 \pm 6.0$ & 0.134 \\
\hline Duration of vegetarian diet (yrs) & $10.4 \pm 8.0$ & - & - \\
\hline Systolic BP (mmHg) & $116.0 \pm 14.0$ & $126.0 \pm 15.0$ & $<0.001^{\neq}$ \\
\hline Diastolic BP (mmHg) & $71.0 \pm 11.0$ & $79.0 \pm 9.0$ & $<0.001^{\ddagger}$ \\
\hline $\mathrm{BMI}\left(\mathrm{kg} / \mathrm{m}^{2}\right)$ & $23.6 \pm 4.0$ & $24.4 \pm 2.7$ & $0.037^{\dagger}$ \\
\hline Weight $(\mathrm{kg})$ & $66.34 \pm 13.27$ & $71.42 \pm 8.43$ & $<0.001^{\dagger}$ \\
\hline Waist Circumference $(\mathrm{cm})$ & $81.7 \pm 10.6$ & $80.7 \pm 6.9$ & $0.299^{\dagger}$ \\
\hline Waist to hip ratio & $0.88 \pm 0.06$ & $0.86 \pm 0.05$ & $0.028^{\dagger}$ \\
\hline Triglyceride (mg/dl) & $1.13 \pm 0.68$ & $1.38 \pm 0.87$ & $0.004^{\ddagger}$ \\
\hline Total cholesterol (mg/dl) & $4.26 \pm 0.63$ & $5.01 \pm 0.86$ & $<0.001^{\neq}$ \\
\hline HDL-cholesterol (mg/dl) & $1.12 \pm 0.18$ & $1.23 \pm 0.22$ & $<0.001^{\ddagger}$ \\
\hline LDL- cholesterol (mg/dl) & $2.59 \pm 0.56$ & $3.11 \pm 0.80$ & $<0.001^{\ddagger}$ \\
\hline $\mathrm{ApoA}_{1}(\mathrm{~g} / \mathrm{L})$ & $1.06 \pm 0.11$ & $1.23 \pm 0.14$ & $<0.001^{\ddagger}$ \\
\hline ApoB (g/L) & $0.75 \pm 0.15$ & $0.88 \pm 0.20$ & $<0.001^{\ddagger}$ \\
\hline Fasting blood glucose (mmol/L) & $4.72 \pm 0.68$ & $5.03 \pm 0.58$ & $<0.001^{\ddagger}$ \\
\hline Fasting insulin (ng/ml) & $7.99 \pm 6.64$ & $7.08 \pm 3.68$ & $0.135^{\ddagger}$ \\
\hline HOMA-IR $\delta$ & $1.75 \pm 1.79$ & $1.60 \pm 0.85$ & $0.349^{\ddagger}$ \\
\hline Homocysteine (umol/L) $\delta$ & $75.9 \pm 19.4$ & $124.9 \pm 45.0$ & $<0.001^{\ddagger}$ \\
\hline C-reactive protein $(\mathrm{ng} / \mathrm{ml}) \delta$ & $21.8 \pm 8.9$ & $21.0 \pm 7.9$ & $0.383^{\ddagger}$ \\
\hline Albumin ( $\mathrm{g} / \mathrm{L})$ & $49.4 \pm 3.5$ & $50.6 \pm 2.4$ & $0.001^{\ddagger}$ \\
\hline Uric acid $(\mathrm{mg} / \mathrm{dl}) \delta$ & $334.2 \pm 65.7$ & $357.8 \pm 77.3$ & $0.005^{\ddagger}$ \\
\hline$\gamma$-glutamyltransferase $(\mathrm{IU} / \mathrm{L}) \delta$ & $20.2 \pm 13.4$ & $30.4 \pm 16.8$ & $<0.001^{\ddagger}$ \\
\hline Intima-media thickness $(\mathrm{cm}) \delta$ & $0.59 \pm 0.16$ & $0.63 \pm 0.10$ & $0.014^{\ddagger}$ \\
\hline
\end{tabular}

Data are shown as mean \pm SD. Paired student's t-test, + For adjusted age; ₹ For adjusted age, BMl, and smoking, drinking, history of diabetes, history of hypertension, and history of hyperlipemia. $\delta$ Analysis performed on log-transformed data. 


\section{Associations between tertiles of age of starting vegetarian diet and metabolic parameters}

The vegetarians were divided into three tertiles according to age of starting the diet $(<17$ years, 17 to $\leq 22$ years, $>22$ years). The TG and HOMA-IR had shown no difference between distinct tertlies of age of starting vegetarian diet (Table 2). Compared to the omnivores, each tertile had significantly lower TC, LDL-C, systolic $\mathrm{BP}$ and diastolic BP when controlling for age, even after age, smoking, drinking, duration of vegetarian diet, history of diabetes, history of hypertension, and history of hyperlipemia had been adjusted. Each tertile had significantly lower HDL-C compared to the omnivores, while the HDL-C had showed no difference after adjusting age, smoking, drinking, duration of vegetarian diet, history of diabetes, history of hypertension, and history of hyperlipemia. As far as IMT was concerned, each tertlie of age of starting vegetarian diet had thinner IMT compare to the omnivores, after adjusting for multivariate factors (age, smoking, drinking, duration of vegetarian diet, history of diabetes, history of hypertension, and history of hyperlipemia)

\section{Associations between tertiles of duration of vegetarian diet and metabolic parameters}

When the vegetarians were divided according to duration of vegetarian diet ( $<6$ years, 6 to $\leq 11$ years, $>11$ years), the vegetarians in each tertile had significantly lower $\mathrm{TC}$, HDL-C, LDL-C, systolic BP and diastolic BP after controlling for age compared to the omnivores (Table 3). The vegetarians also had lower TC, LDL-C and diastolic $\mathrm{BP}$ compared to the omnivores when controlling for age, smoking, drinking, history of diabetes, history of hypertension, and history of hyperlipemia. After adjusting for multivariate variables, TG, HDL-C, HOMA-IR and systolic BP had shown no difference between distinct tertlies of the vegetarians and of the omnivores, while only tertile 1 (< 6 years) had lower systolic BP and tertile 2 ( 6 to $\leq 11$ years) had lower HDL-C comparing to the omnivores. As for IMT, only the tertile 1 ( $<6$ years) and tertile 2 ( 6 to $\leq$ 11 years) had shown thinner IMT as compared to the omnivores, and the tertile 3 had not shown an advantage of reducing IMT.

Correlation analysis showed that duration of vegetarian diet correlated with many metabolic parameters, such as FBG, TC, TG, HDL-C, LDL-C BMI, systolic BP, diastolic BP, HOMA-IR, HCY, CRP, UA and IMT (data not shown). By logistic regression analysis after adjusted for age, FBG, BMI, systolic BP, diastolic BP, HOMA-IR, HCY, CRP, UA, smoking, drinking and history of disease, the odds ratio for IMT in the tertile 2 and tertile 3 were significantly decreased compared to the omnivores (Table 4 and Figure 1). However, these relations after further adjustments for TC, TG, HDL-C and LDL-C disappeared $(P=0.140)$.

\section{Discussion}

Vegetarian diet had been shown in studies to have beneficial effects on CVD prevention by improving metabolic profile and cardiovascular risk such as blood pressure, lipid profile, insulin sensitivity and vascular dilatory function $[3,12,13]$. In this study, the vegetarians had thinner IMT compared to the omnivores. Our results demonstrated that the reduction of IMT is dependent on duration of vegetarian diet; however, the effects on reduction of IMT are not significant in those whose duration is beyond 11 years.

Diseases like hypertension and dyslipidemia are important causes of CVD and considered as conventional cardiovascular risk factors. Our data showed that vegetarians had lower systolic $\mathrm{BP}$, diastolic $\mathrm{BP}$ and lower serum TC, TG, LDL-C and UA compared to the omnivores. Differences in dietary habits have reflected in

Table 2 Metabolic parameters by tertiles of age of starting vegetarian diet

\begin{tabular}{|c|c|c|c|c|c|}
\hline & \multicolumn{4}{|c|}{ Tertiles of age of starting vegetarian diet } & \multirow[t]{2}{*}{$P^{*}$} \\
\hline & $\begin{array}{l}\text { Omnivores } \\
(n=129)\end{array}$ & Vegetarian $<17$ yrs $(n=62)$ & $17 \leqq$ Vegetarian $\leqq 22$ yrs $(n=53)$ & $\begin{array}{c}\text { Vegetarian }>22 \\
\text { yrs }(n=56)\end{array}$ & \\
\hline Total cholesterol (mg/dl) & $4.89(4.70-5.09)$ & $4.45(4.19-4.72)^{\dagger}$ & $4.32(4.09-4.56)^{\ddagger}$ & $4.32(4.08-4.56)^{\ddagger}$ & 0.002 \\
\hline Triglyceride (mg/dl) & $1.38(1.07-1.68)$ & $1.41(1.00-1.83)$ & $1.23(0.86-1.60)$ & $1.32(0.95-1.70)$ & 0.86 \\
\hline HDL-cholesterol (mg/dl) & $1.19(1.14-1.25)$ & $1.19(1.11-1.26)$ & $1.16(1.09-1.22)$ & $1.13(1.06-1.20)$ & 0.48 \\
\hline LDL-cholesterol (mg/dl) & $3.07(2.89-3.24)$ & $2.63(2.39-2.87)^{\dagger}$ & $2.61(2.40-2.82)^{\ddagger}$ & $2.57(2.36-2.79)^{\ddagger}$ & 0.006 \\
\hline HOMA-IR $\delta$ & $1.40(0.76-2.04)$ & $2.53(1.66-3.40)$ & $2.17(1.40-2.94)$ & $2.01(1.22-2.79)$ & 0.39 \\
\hline Systolic BP (mmHg) & $128(124-132)$ & $114(108-119)^{\ddagger}$ & $114(110-120)^{\ddagger}$ & $117(112-122)^{\ddagger}$ & 0.001 \\
\hline Diastolic BP (mmHg) & $79(77-82)$ & $71(67-74)^{\ddagger}$ & $71(68-74)^{\ddagger}$ & $73(69-76)^{\ddagger}$ & 0.003 \\
\hline IMT $(\mathrm{cm}) \delta$ & $0.62(0.60-0.64)$ & $0.57(0.55-0.60)^{\dagger}$ & $0.57(0.54-0.59)^{\ddagger}$ & $0.58(0.55-0.60)^{\ddagger}$ & 0.016 \\
\hline C-reactive protein $(\mathrm{ng} / \mathrm{ml}) \delta$ & 18.8(16.9-20.9) & 23.3(20.1-27.0) & 21.4(18.8-24.3) & $17.4(15.3-19.8)$ & 0.050 \\
\hline Homocysteine (umol/L) $\delta$ & $120.8(111.8-129.8)$ & $79.2(66.7-91.7)^{\ddagger}$ & $85.9(75.0-96.8)^{\ddagger}$ & $76.6(65.6-87.6)^{\ddagger}$ & $<0.001$ \\
\hline
\end{tabular}

Data are means $(95 \% \mathrm{CL})$ unless indicated otherwise. P-Value is the difference among three groups using ANOVA test. * Adjusted for age, smoking, drinking, history of diabetes, history of hypertension, and history of hyperlipemia. $+P<0.05$ vs. Omnivores, $\neq P<0.01$ vs. Omnivores. $\delta$ Analysis performed on logtransformed data. 
Table 3 Metabolic parameters by tertiles of duration of vegetarian diet

\begin{tabular}{|c|c|c|c|c|c|}
\hline & \multicolumn{4}{|c|}{ Tertiles of duration of vegetarian diet } & \multirow[t]{2}{*}{$P^{*}$} \\
\hline & $\begin{array}{l}\text { Omnivores } \\
(n=129)\end{array}$ & $\begin{array}{c}0<\text { Vegetarian }<6 \text { yrs } \\
(n=55)\end{array}$ & $\begin{array}{c}6 \leqq \text { Vegetarian } \leqq 11 \text { yrs } \\
(n=61)\end{array}$ & $\begin{array}{c}\text { Vegetarian }>=12 \text { yrs } \\
(n=55)\end{array}$ & \\
\hline $\begin{array}{l}\text { Total cholesterol } \\
(\mathrm{mg} / \mathrm{dl})\end{array}$ & $4.95(4.79-5.10)$ & $4.33(4.11-4.54)^{\ddagger}$ & $4.39(4.18-4.59)^{\ddagger}$ & $4.26(4.02-4.50)^{\ddagger}$ & $<0.001$ \\
\hline Triglyceride (mg/dl) & $1.39(1.15-1.64)$ & 1.04(0.70-1.37) & $1.61(1.29-1.92)$ & $1.26(0.88-1.63)$ & 0.056 \\
\hline $\begin{array}{l}\text { HDL-cholesterol } \\
(\mathrm{mg} / \mathrm{dl})\end{array}$ & $1.22(1.18-1.26)$ & $1.18(1.12-1.24)$ & $1.11(1.05-1.16)^{\ddagger}$ & $1.14(1.07-1.21)$ & 0.026 \\
\hline $\begin{array}{l}\text { LDL- cholesterol } \\
(\mathrm{mg} / \mathrm{dl})\end{array}$ & $3.09(2.95-3.23)$ & $2.68(2.48-2.87)^{\ddagger}$ & $2.55(2.36-2.73)^{\ddagger}$ & $2.55(2.33-2.76)^{\ddagger}$ & $<0.001$ \\
\hline HOMA-IR $\delta$ & $1.71(1.19-2.22)$ & $1.70(0.99-2.41)$ & $2.34(1.68-3.01)$ & $1.97(1.18-2.76)$ & 0.440 \\
\hline Systolic BP (mmHg) & 124(121-128) & $116(111-121)^{\ddagger}$ & 119(115-123) & $119(114-124)$ & 0.048 \\
\hline Diastolic BP (mmHg) & $78(76-80)$ & $72(69-75)^{\ddagger}$ & $73(70-76)^{\dagger}$ & $73(70-76)^{\dagger}$ & 0.021 \\
\hline IMT $(\mathrm{cm}) \delta$ & $0.62(0.60-0.64)$ & $0.57(0.55-0.59)^{\dagger}$ & $0.57(0.55-0.59)^{\dagger}$ & $0.60(0.57-0.62)$ & 0.047 \\
\hline $\begin{array}{l}\text { C-reactive protein } \\
(\mathrm{ng} / \mathrm{ml}) \delta\end{array}$ & 21.6(20.1-23.1) & $22.7(20.2-25.1)$ & 21.9(19.7-24.2) & 20.0(17.4-22.6) & 0.581 \\
\hline $\begin{array}{l}\text { Homocysteine } \\
\text { (umol/L) } \delta\end{array}$ & $125.4(119.3-131.5)$ & 80.9(70.9-90.8) & $77.9(68.7-87.0)$ & $72.6(62.0-83.1)$ & $<0.001$ \\
\hline
\end{tabular}

Data are means $(95 \% \mathrm{CL})$ unless indicated otherwise. P-Value is the difference among three groups using ANOVA test. * Adjusted for age, smoking, drinking, history of diabetes, history of hypertension, and history of hyperlipemia. $+P<0.05$ vs. omnivores, $\neq P<0.01$ vs. Omnivores. $\delta$ Analysis performed on logtransformed data.

these biochemical parameters, which was favorable in vegetarians [14-16]. In the present study, the vegetarians had lower BMI and weight, but larger waist to hip ratio (WHR) than omnivores. Our data supported vegetarian diets were associated with weight loss compared with omnivores [17,18]; in contrast, Chen CW et al. showed that there was no significant difference in BMI and weight between the two groups. High uric acid concentrations are associated with an increased risk of CVD [19]. The high content of nucleic acids in meat results in the formation of more purine-derived uric acid in meat eaters; thus, the lower uric acid concentration in our vegetarian group is expected, this help minimize the risk of CVD.

Dietary patterns modifications had been reported to be associated with reduced circulating levels of acute phase proteins and cytokines [20-22], but they had not been analyzed in parallel for their relative contribution and relevance to reductions in proinflammatory markers. Plasma level of C-reactive protein (CRP) is considered as the predictive value of inflammatory markers on cardiovascular risk [23]; vegetarians probably would not have this value compared to omnivores in our study. Some diabetes prevention studies had shown that lifestyle intervention achieved median reductions in CRP levels $[20,24]$, and Szeto et al. also found that vegetarian diet was associated with lower concentrations of CRP [25]. Actually, weight loss is an important determinant in lowering CRP level [26]. While the weights of the vegetarians was only reduced slightly in the present study, however, the WHRs, a central obesity indicator, were larger in the vegetarians than in the omnivores, and this unfavorable indicator in the vegetarians might counteract the benefit of weight loss on antiinflammation.

Interestingly, we found markedly lower $\gamma$-GT in the vegetarians than in the omnivores. $\gamma-\mathrm{GT}$ is highly related to oxidative stress which plays important roles in both metabolic diseases and CVD. Elevated $\gamma$-GT has been considered to be a significant independent predictor of impaired glucose tolerance and diabetes mellitus, and associated with all the features of metabolic

Table 4 Risk of carotid atherosclerosis according to tertile of duration of vegetarian diet

\begin{tabular}{|c|c|c|c|c|c|}
\hline & \multicolumn{4}{|c|}{ OR (95\% CL) } & \multirow[t]{2}{*}{$P$} \\
\hline & $\begin{array}{l}\text { Omnivores } \\
(n=129)\end{array}$ & $\begin{array}{c}0<\text { Vegetarian }<6 \text { yrs } \\
(n=55)\end{array}$ & $\begin{array}{c}6 \leqq \text { Vegetarian } \leqq 11 \\
\text { yrs }(n=61)\end{array}$ & $\begin{array}{c}\text { Vegetarian }>=12 \text { yrs } \\
(n=55)\end{array}$ & \\
\hline Model 1 & 1 & $0.22(0.06-0.83)$ & $0.14(0.04-0.47)$ & $0.51(0.18-1.44)$ & 0.005 \\
\hline Model 2 & 1 & $0.27(0.07-1.02)$ & $0.18(0.05-0.60)$ & $0.60(0.21-1.73)$ & 0.025 \\
\hline Model 3 & 1 & $0.34(0.09-1.38)$ & $0.25(0.07-0.92)$ & $0.74(0.24-2.27)$ & 0.140 \\
\hline
\end{tabular}

Data are OR $(95 \% \mathrm{Cl})$ unless otherwise indicated. Model 1, Adjustments for age, BMI, HOMA-IR, smoking, drinking, history of diabetes, history of hypertension and history of hyperlipemia; model 2, model 1 + Adjustment for Systolic BP and Diastolic BP, model 3, model 2+ Adjustment for Total cholesterol, Triglyceride, HDLcholesterol and LDL-cholesterol. 


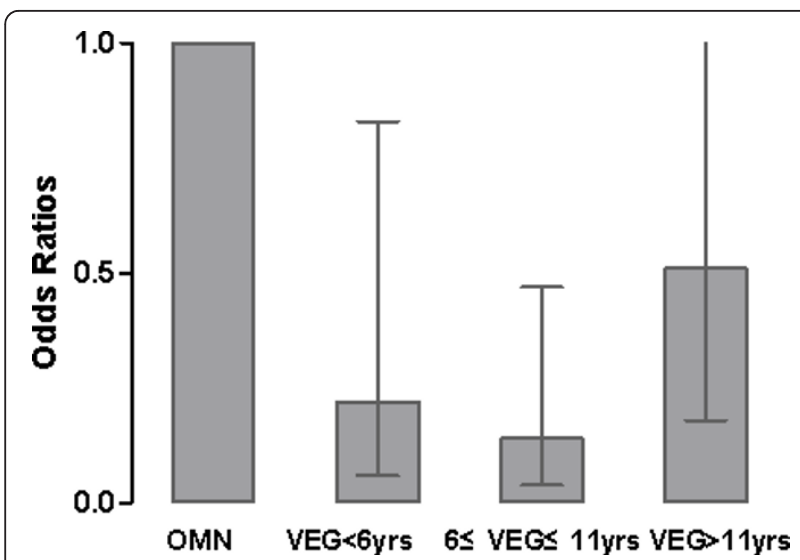

Figure 1 Risk of cardiovascular disease by tertiles of duration of vegetarian diet. Adjusted for age, BMl, HOMA-IR, smoking, drinking, history of diabetes, history of hypertension, and history of hyperlipemia. All ORs are statistically significant. OMN, ominivores; VEG, vegetarians.

syndrome [27]. HCY is an independent risk factor for arterial and venous disease, and a graded association appears to exist between HCY and mortality $[28,29]$. Mezzano et al. found that mean fasting HCY was higher in vegetarians than in controls [30]; conversely, our study showed that the Chinese vegetarians had lower HCY compared to the omnivores. This finding that supports better metabolic parameters in Chinese vegetarians is likely to predict lower risk of CVD.

Carotid IMT is strongly associated with CVD and its risk factors [31]; therefore it could provide a surrogate end point to assess early atherosclerosis $[7,8]$. In this study, there were significant differences in carotid IMT between the two groups, IMT in the vegetarians was remarkably thinner than in the omnivores, this is in line with a cross-sectional study which reported long-term low-calorie low-protein vegetarian diet led to significant thinner IMT of carotid arteries [2]. Further analysis showed that reduction of IMT was not dependent on starting age of vegetarian diet but the duration. When the vegetarians were divided into three tertiles according to age of starting vegetarian diet, each tertile showed reducing TC, LDL-C, systolic BP, diastolic $\mathrm{BP}$ and carotid IMT. However, the TG, HDL and HOMA-IR showed no difference after adjusting for duration of vegetarian diet, thereby, vegetarians, independent of their age of starting vegetarian diet, have thinner IMT and lower risk of CVD

However, when the vegetarians were divided according to the duration of vegetarian diet, only those in tertile 1 and 2 ( $<6$ years and 6 to $\leq 11$ years) had significantly thinner IMT compared to the omnivores, while tertile 3 (> 11 years) did not show beneficial effect. Similarly, each tertile of duration of vegetarian diet has reduced
TC, LDL-C and diastolic BP. Logistic regression analysis showed that vegetarian diet played a key role in reducing IMT by improving lipid profile. Few previous studies have discussed the association between duration of vegetarian diet and metabolic cardiovascular risk factor. For vegetarians especially vegans, their diets are deficient in several nutrients including protein, iron, zinc, calcium, vitamin B12 and A, n-3 fatty acids and iodine, this may partly counteract the benefit from this diet habit. Vegetarian diets are also relatively low in $\alpha$-linolenic acid and provide little eicosapentaenoic acid (EPA) as well as docosahexaenoic acid (DHA) which might exert potent cardioprotective effects [32]. Thus the nutrition status from long-term vegetarian diet may counteract the known cardiovascular health benefits from it. However, the exact explanations remain unclear.

In conclusion, long-term consumption of a low-calorie low-protein vegetarian diet is associated with a decrease in multiple cardiovascular risk factors such as BMI, blood pressure and lipid profile. Moreover, comparing to omnivorous diet, vegetarian diet improves lipid profile that would lead to beneficial effects on carotid IMT, and this appeared to be correlated with the duration of vegetarian diet. However, long-term vegetarian diet, although beneficial on the reduction of IMT, it is deficient in some other nutrients that need to be taken into consideration.

\section{Additional material}

Additional file 1: Daily dietary intakes of vegetarians and

omnivores. Comparison of dietary components of vegetarians and omnivores.

\section{Acknowledgements}

We are grateful to the consideration and cooperation of all the participants of the study. The authors would like to acknowledge Prof. Xiao-Ying Li from Rui-jin Hospital Affiliated to Shanghai Jiaotong University, for his advices in the present project. This study is supported by the grants from the Natural Science Foundation of China (NO. 81000320), the Natural Science Foundation of Fujian Province and Xiamen (NO. 20090016 and 3502Z20104026) and the Youth Foundation of Fujian Provincial Health Department (NO.2010-2-86).

\section{Author details}

${ }^{1}$ Fujian Academy of Integrative Medicine, Fujian University of Traditional Chinese Medicine, 1 Hua-Tuo Road, Shang-Jie Town, Fuzhou, 350108, PR China. ${ }^{2}$ Xiamen Diabetes Institute, Department of Diabetes, The First Affiliated Hospital of Xiamen University, 55 Zhen-Hai Road, Xiamen 361003, PR China.

\section{Authors' contributions}

SYY conceived of the study, involved in the coordination and revised the manuscript. HJZ participated in the design of the study, performed the statistical analysis and drafted the manuscript. SYS performed the statistical analysis and participated in clinical assessment and laboratory measurements. LYW carried out dietary assessment of subjects. BY participated in clinical assessment and measurement of carotid artery IMT. CQL performed clinical assessment and laboratory measurements. WZ 
participated in clinical assessment and laboratory measurements. XJL participated in its design and coordination. All authors read and approved the final manuscript

\section{Competing interests}

The authors declare that they have no competing interests.

Received: 5 June 2011 Accepted: 19 September 2011

Published: 19 September 2011

\section{References}

1. Key TJ, Fraser GE, Thorogood M, Appleby PN, Beral V, Reeves G, Burr ML, Chang-Claude J, Frentzel-Beyme R, Kuzma JW, Mann J, McPherson K: Mortality in vegetarians and nonvegetarians: detailed findings from a collaborative analysis of 5 prospective studies. Am J Clin Nutr 1999, 70:516S-524S.

2. Fontana L, Meyer TE, Klein S, Holloszy JO: Long-term low-calorie lowprotein vegan diet and endurance exercise are associated with low cardiometabolic risk. Rejuvenation Res 2007, 10:225-234.

3. Rosa EM, Scatola RP, Possa R: Cardiovascular risk in vegetarians and omnivores: a comparative study. Ara Bras Cardiol 2008, 91:287-268, 263; author reply 263-264.

4. Sacks FM, Ornish D, Rosner B, McLanahan S, Castelli WP, Kass EH: Plasma lipoprotein levels in vegetarians. The effect of ingestion of fats from dairy products. JAMA 1985, 254:1337-1341.

5. Key TJ, Appleby PN, Davey GK, Allen NE, Spencer EA, Travis RC: Mortality in British vegetarians: review and preliminary results from EPIC-Oxford. Am J Clin Nutr 2003, 78:533S-538S.

6. Key TJ, Appleby PN, Spencer EA, Travis RC, Roddam AW, Allen NE: Mortality in British vegetarians: results from the European Prospective Investigation into Cancer and Nutrition (EPIC-Oxford). Am J Clin Nutr 2009, 89:1613S-1619S.

7. Lorenz MW, Markus HS, Bots ML, Rosvall M, Sitzer M: Prediction of clinical cardiovascular events with carotid intima-media thickness: a systematic review and meta-analysis. Circulation 2007, 115:459-467.

8. Lorenz MW, von Kegler S, Steinmetz H, Markus HS, Sitzer M: Carotid intimamedia thickening indicates a higher vascular risk across a wide age range: prospective data from the Carotid Atherosclerosis Progression Study (CAPS). Stroke 2006, 37:87-92.

9. Du S, Lu B, Zhai F, Popkin BM: A new stage of the nutrition transition in China. Public Health Nutr 2002, 5:169-174.

10. Zhai F, Wang H, Du S, He Y, Wang Z, Ge K, Popkin BM: Prospective study on nutrition transition in China. Nutr Rev 2009, 67(Suppl 1):S56-61.

11. Simon A, Gariepy J, Chironi G, Megnien JL, Levenson J: Intima-media thickness: a new tool for diagnosis and treatment of cardiovascular risk. $J$ Hypertens 2002, 20:159-169.

12. Lin CL, Fang TC, Gueng MK: Vascular dilatory functions of ovolactovegetarians compared with omnivores. Atherosclerosis 2001 158:247-251.

13. Sebekova K, Boor P, Valachovicova M, Blazicek P, Parrak V, Babinska K, Heidland A, Krajcovicova-Kudlackova M: Association of metabolic syndrome risk factors with selected markers of oxidative status and microinflammation in healthy omnivores and vegetarians. Mol Nutr Food Res 2006, 50:858-868,

14. Chen $C W$, Lin $Y L$, Lin $T K$, Lin $C T$, Chen $B C$, Lin CL: Total cardiovascular risk profile of Taiwanese vegetarians. Eur J Clin Nutr 2008, 62:138-144.

15. Teixeira Rde C, Molina Mdel C, Zandonade E, Mill JG: Cardiovascular risk in vegetarians and omnivores: a comparative study. Arq Bras Cardiol 2007, 89:237-244.

16. Waldmann A, Koschizke JW, Leitzmann C, Hahn A: German vegan study: diet, life-style factors, and cardiovascular risk profile. Ann Nutr Metab 2005, 49:366-372.

17. Berkow SE, Barnard N: Vegetarian diets and weight status. Nutr Rev 2006, 64:175-188.

18. Robinson-O'Brien R, Perry CL, Wall MM, Story M, Neumark-Sztainer D: Adolescent and young adult vegetarianism: better dietary intake and weight outcomes but increased risk of disordered eating behaviors. $J$ Am Diet Assoc 2009, 109:648-655.

19. Bickel C, Rupprecht HJ, Blankenberg S, Rippin G, Hafner G, Daunhauer A Hofmann KP, Meyer J: Serum uric acid as an independent predictor of mortality in patients with angiographically proven coronary artery disease. Am J Cardiol 2002, 89:12-17.

20. Haffner S, Temprosa M, Crandall J, Fowler S, Goldberg R, Horton E, Marcovina S, Mather K, Orchard T, Ratner R, Barrett-Connor E: Intensive lifestyle intervention or metformin on inflammation and coagulation in participants with impaired glucose tolerance. Diabetes 2005, 54:1566-1572.

21. Fung TT, McCullough ML, Newby PK, Manson JE, Meigs JB, Rifai N, Willett WC, Hu FB: Diet-quality scores and plasma concentrations of markers of inflammation and endothelial dysfunction. Am J Clin Nutr 2005, 82:163-173.

22. Schulze MB, Hoffmann K, Manson JE, Willett WC, Meigs JB, Weikert C, Heidemann C, Colditz GA, Hu FB: Dietary pattern, inflammation, and incidence of type 2 diabetes in women. Am J Clin Nutr 2005, 82:675-684 quiz 714-675.

23. Ridker PM, Cushman M, Stampfer MJ, Tracy RP, Hennekens CH: Plasma concentration of C-reactive protein and risk of developing peripheral vascular disease. Circulation 1998, 97:425-428.

24. Herder C, Peltonen M, Koenig W, Sutfels K, Lindstrom J, Martin S, llanneParikka P, Eriksson JG, Aunola S, Keinanen-Kiukaanniemi S, Valle TT, Uusitupa M, Kolb H, Tuomilehto J: Anti-inflammatory effect of lifestyle changes in the Finnish Diabetes Prevention Study. Diabetologia 2009, 52:433-442.

25. Szeto YT, Kwok TC, Benzie IF: Effects of a long-term vegetarian diet on biomarkers of antioxidant status and cardiovascular disease risk. Nutrition 2004, 20:863-866.

26. Selvin E, Paynter NP, Erlinger TP: The effect of weight loss on C-reactive protein: a systematic review. Arch Intern Med 2007, 167:31-39.

27. Nannipieri M, Gonzales C, Baldi S, Posadas R, Williams K, Haffner SM, Stern MP, Ferrannini E: Liver enzymes, the metabolic syndrome, and incident diabetes: the Mexico City diabetes study. Diabetes Care 2005, 28:1757-1762.

28. von Eckardstein A, Assmann G: Plasma homocysteine levels and mortality in patients with coronary artery disease. N Engl J Med 1997. 337:1632-1633

29. Boers GH: Hyperhomocysteinemia as a risk factor for arterial and venous disease. A review of evidence and relevance. Thromb Haemost 1997, 78:520-522.

30. Mezzano D, Munoz X, Martinez C, Cuevas A, Panes O, Aranda E, Guasch V, Strobel P, Munoz B, Rodriguez S, Pereira J, Leighton F: Vegetarians and cardiovascular risk factors: hemostasis, inflammatory markers and plasma homocysteine. Thromb Haemost 1999, 81:913-917.

31. Su TC, Jeng JS, Chien KL, Sung FC, Hsu HC, Lee YT: Hypertension status is the major determinant of carotid atherosclerosis: a community-based study in Taiwan. Stroke 2001, 32:2265-2271.

32. Davis BC, Kris-Etherton PM: Achieving optimal essential fatty acid status in vegetarians: current knowledge and practical implications. Am J Clin Nutr 2003, 78:640S-646S.

\section{doi:10.1186/1743-7075-8-63}

Cite this article as: Yang et al:: Relationship of carotid intima-media thickness and duration of vegetarian diet in Chinese male vegetarians. Nutrition \& Metabolism 2011 8:63.

\section{Submit your next manuscript to BioMed Central and take full advantage of:}

- Convenient online submission

- Thorough peer review

- No space constraints or color figure charges

- Immediate publication on acceptance

- Inclusion in PubMed, CAS, Scopus and Google Scholar

- Research which is freely available for redistribution 